\title{
Procedimentos de atenuação no inglês falado: o discurso do presidente Obama
}

\author{
Vanessa Hagemeyer Burgo \\ Universidade Federal de Mato Grosso do Sul \\ vanessahburgo@hotmail.com \\ João Vieira da Silva Neto \\ PPG-Universidade Federal de Mato Grosso do Sul \\ joaovieiraneto@yahoo.com.br
}

\begin{abstract}
Resumo
O objetivo deste trabalho é analisar os procedimentos de atenuação presentes na fala do presidente Barack Obama e a forma como são empregados a favor da construção de sua imagem pública positiva. $\mathrm{O}$ aporte teórico da pesquisa tem embasamento nos princípios da Análise da Conversação e a transcrição dos dados foi realizada de acordo com as convenções sugeridas por Preti (2003). O corpus é formado por duas entrevistas nas quais o presidente expressa diferentes pontos de vista acerca de um assunto polêmico: o casamento homossexual. As entrevistas televisivas configuram uma forma de interação social significativa, uma vez que por meio delas, busca-se a obtenção de respostas, a troca de informação, experiências e juízos de valores dos interactantes. Dentro dessa dinâmica, os diálogos são conduzidos, de forma geral, entre entrevistador e entrevistado, entrevistado e público, e entrevistador e audiência. Os resultados demonstraram que esses recursos influenciam a atitude linguística do entrevistado, sobretudo quando exposto, diretamente, a um grande público. São estratégias sociointeracionais destinadas à redução de possíveis ameaças à imagem que o falante deseja preservar, para obter a aprovação dos ouvintes, e para garantir o resguardo do que não pretende ver exibido.

Palavras-chave: Procedimentos de atenuação; inglês falado; estratégias sociointeracionais.
\end{abstract}




\begin{abstract}
The aim of this work is to analyze the mitigation devices that President Barack Obama employs while speaking, and how they are used for the construction of his positive public image. The theoretical framework of this research is based on the principles of Conversation Analysis, and the transcription of data was carried out according to the conventions suggested by Preti (2003). The corpus is composed of two interviews in which President Obama expresses different points of view about a polemical issue: homosexual marriage. Television interviews make up a significant form of social interaction, since through them one intends to obtain answers, exchange information, experiences and value judgments of the interactants. In this dynamic, dialogues are conducted, in general, between interviewer and interviewee, interviewee and audience, and interviewer and audience. Results show that these resources influence the interviewee's linguistic attitude, especially when he or she is directly exposed to a wide audience. These are sociointeractional strategies that are drawn up to reduce potential threats to the image that the speaker wants to preserve, to get approval from the listeners, and to ensure the defense of what he or she does not want to see exhibited.
\end{abstract}

Keywords: Mitigation devices; spoken English; sociointeractional strategies.

\title{
1. Introdução
}

Muitos são os estudos acerca da atenuação linguística e dos processos utilizados pelos falantes para diminuir a força ilocutória de seus enunciados. Visando a contribuir com essas pesquisas, o presente estudo analisa os procedimentos e os marcadores de atenuação utilizados pelo presidente dos Estados Unidos Barack Obama para preservar sua imagem pública durante uma interação.

Para compreender como o presidente utiliza esses marcadores e procedimentos para amenizar seus enunciados e distanciar sua imagem de assuntos polêmicos, adotou-se uma abordagem pragmática da linguagem voltada para o âmbito político que trata exclusivamente de um determinado tópico: o casamento entre pessoas do mesmo sexo. As entrevistas 
selecionadas para a análise são do ano de 2004, momento em que Obama concorria à presidência do senado, e do ano de 2012, período no qual ele concorria à reeleição. As entrevistas possibilitaram analisar os processos de atenuação existentes em uma interação, pois, de acordo com Rosa (1992, p. 8):

Todo discurso, oral ou escrito, deriva da interação entre indivíduos socialmente organizados, e apresenta em sua estrutura diversos elementos ligados intrinsecamente a interação em processo, seja ela claramente observável ou não. [...] Quando lidamos com a linguagem falada, observamos que o locutor utiliza vários comportamentos verbais ritualizados para assegurar a condução satisfatória da interação em que está envolvido. $\mathrm{O}$ uso dos procedimentos de atenuação corresponde a um desses comportamentos.

Os discursos de políticos, de um modo geral, são meios produtivos para se analisar a interação e os procedimentos utilizados por eles para se distanciarem de assuntos desconfortáveis ou para enaltecerem seus atos. Por se tratar de um assunto polêmico que envolve diversos segmentos da sociedade, por vezes, com posicionamentos opostos, percebe-se nas entrevistas uma preocupação, por parte do presidente, em resguardar sua face perante a sociedade e a oposição política.

Entende-se por face a autoimagem pública que cada indivíduo constrói de si mesmo e que pretende ver preservada. Segundo Goffman (1974, p. 09), face é o valor social positivo que uma pessoa efetivamente reivindica para si por meio da linha de ação que os outros pressupõem que ela tenha adotado durante um contato específico. "A face é uma imagem de si delineada segundo certos atributos sociais aprovados"1. Essa imagem, no entanto, é compartilhada, pois, oferecer uma boa imagem profissional, por exemplo, é oferecer uma boa imagem de si próprio.

\footnotetext{
${ }^{1}$ La face est une image du moi délinéée selon certains attributs sociaux approuvés.
} 
As entrevistas televisivas voltadas a figuras políticas em situação de desgaste estão repletas de procedimentos atenuadores. Como forma de aproximação do público, entrevistador e entrevistado fazem uso intenso de estratégias discursivas semelhantes às de uma conversação espontânea. Observa-se que, no caso das entrevistas televisivas, ocorre uma interação mais assimétrica se as comparamos com uma conversa cotidiana entre amigos, por exemplo.

Com o objetivo de discutirmos as estratégias sociointeracionais empregadas no texto falado em inglês, evidenciaremos as propriedades identificadoras da atenuação na atividade interacional, tendo como corpus duas entrevistas de diferentes momentos: a primeira, do ano de 2004, período em que o presidente Barack Obama estava em campanha eleitoral para a presidência do senado, e a segunda, de maio de 2012, em que já existe a preocupação com a reeleição para a presidência.

Cabe salientar que o aporte teórico que conduziu esta investigação baseia-se nos princípios da Análise da Conversação, com vistas à análise das estruturas de participação e à observação dos procedimentos atenuadores adotados pelo presidente americano durante entrevistas televisivas. Dentre os procedimentos de atenuação, dedicamos especial atenção aos marcadores de opinião, de distanciamento e aos marcadores prefaciadores, entendidos como marcadores que servem de prefácio para outros enunciados.

\section{Características dos discursos orais sob análise}

Conforme informado anteriormente, o corpus deste estudo é constituído por duas entrevistas: a primeira (Entrevista 1) foi concedida ao jornalista de televisão Phil Ponce, realizada em 26 de outubro de 2004 (OBAMA, 2004), e a segunda (Entrevista 2), à jornalista Robin Roberts, âncora do programa matinal Good Morning America, da rede $A B C$, em 09 de maio de 2012 (OBAMA, 2012). 
As entrevistas analisadas foram selecionadas por abordarem um tópico polêmico e muito discutido pela sociedade americana. Nos últimos anos, o casamento gay tornou-se uma reivindicação frequente da comunidade homossexual. Abordado constantemente nas entrevistas de campanha eleitoral, o bom desempenho dos candidatos à presidência em relação ao tema pode interferir no resultado das urnas.

Visando a conseguir o apoio político da população homossexual ou de simpatizantes dos movimentos Lésbicas, Gays, Bissexuais, Travestis, Transexuais e Transgêneros (LGBT), o presidente Barack Obama declarou, em uma recente entrevista, ter posicionamento favorável ao casamento de pessoas do mesmo sexo. Entretanto, observou-se, por meio das análises, que essa postura não era a mesma adotada em uma entrevista anterior. Vale ressaltar que o presidente utiliza, com grande frequência, determinados procedimentos e marcadores de atenuação, porém, com intuitos opostos: ora para preservar sua imagem diante dos que estão a seu favor, ora para construí-la, positivamente, diante dos que estão contra.

Na primeira entrevista selecionada, de outubro de 2004, época em que Obama concorria à presidência do senado, Obama empregava diversos procedimentos de atenuação para se distanciar da polêmica envolvendo sua posição acerca do casamento gay e, assim, não se indispor, nem com os homossexuais e nem com a parcela da população contrária ao assunto. O presidente demonstrou, nessa entrevista, se opor à união homossexual, mas alegou a necessidade de garantir aos homossexuais direitos como visitas hospitalares, transferências de propriedades e não descriminação no trabalho.

Já em 2012, ano em que o presidente concorria à reeleição, seu posicionamento mudou, pois declarou que companheiros do mesmo sexo devem poder se casar. A utilização dos procedimentos e marcadores de atenuação permanecia em sua fala, porém, Obama os utilizava com outro objetivo: o de não arranhar sua face perante a maioria opositora ao casamento entre pessoas do mesmo sexo.

Nas duas entrevistas analisadas, percebe-se uma mudança de opinião referente ao tema. Pode-se observar, por 
meio das transcrições realizadas, uma gradação de opinião por parte do presidente. Em 2004, ele expressou seu ponto de vista ao dizer que: "what I believe is that... is that marriage is between a man and a woman"2 (Obama, 2004) e manteve essa postura durante toda sua campanha presidencial em 2008. Observa-se sua grande mudança de opinião quando, como atual presidente em 2012 e concorrendo à reeleição, ele afirmou que "same-sex couples should be able to get married"3 (OBAMA, 2012).

A decisão de Obama provocou resultados positivos e negativos para sua camapanha, pois passou a adquirir o apoio da comunidade gay. Entretanto, ele perdeu o apoio de uma importante parcela do eleitorado que é contrária ao casamento homossexual. Essa oposição foi feita, principalmente, pela comunidade religiosa que se identificava com o candidato Mitt Romney. O principal adversário de Obama não era favorável a essa questão e, quando foi governador em 2004, lutou contra sua legalização no estado de Massachusetts.

É importante acrescentar, ainda, que as entrevistas em questão são interações assimétricas, pois, entrevistador e entrevistado não possuem o mesmo direito à palavra. Normalmente, existe a predominância da fala do entrevistado, com maior respeito aos turnos conversacionais ${ }^{4}$ por parte do entrevistador.

Além da assimetria da interação, há a predominância da linguagem tipicamente formal que, segundo Rosa (1992, p. 14), deve apresentar "sinais de planejamento verbal, ritmo regular da enunciação, estruturas sintaticamente completas - com pequeno número de pausas, anacolutos e hesitações -, pequeno número de marcadores, troca de turno mais disciplinada, etc".

2 “o que eu acredito é que... é que o casamento seja entre um homem e uma mulher"

3 "casais do mesmo sexo devem poder se casar"

4 Nas palavras de Castilho (2000, p. 36), o turno é conceituado como o "segmento produzido por um falante com direito a voz". Galembeck (2003, p. 65) assevera que turno é a "participação de cada interlocutor", isto é, a oportunidade de falar, tomar a palavra, em algum ponto da conversação. Quando um interlocutor passa de ouvinte a falante, ele dá início ao seu turno.

108 Horizontes de Linguística Aplicada, ano 11, n. 2, jul./dez. 2012 
Embora as entrevistas tenham sido concedidas por uma autoridade, falando acerca de assuntos delicados, e esse contexto já implicaria maior grau de formalidade, a língua falada apresenta certas marcas do processo de elaboração, justamente por ser planejada localmente (no momento de sua execução). Pode-se perceber, portanto, uma grande utilização dos marcadores conversacionais ("well", "bem"), marcadores de opinião ("I think", "eu acho"; "but I also think", "mas eu também acho"), procedimentos de atenuação ("we have a set of traditions in place... that I think... ah need to be preserved"; "nós temos um conjunto de tradições instituídas... que eu acho que... ah precisam ser preservadas"; "but what I also believe", "mas o que eu também acredito"), prefaciadores ("Well... what I believe", "Bem... o que eu acredito") e marcas de aprovação discursiva ("you know", "sabe"). A grande incidência desses procedimentos foi um dos principais motivos para a realização desse estudo, porém, por delimitação do tema, serão analisados apenas os marcadores de opinião, de distanciamento e os marcadores prefaciadores.

\section{A representação do indivíduo na sociedade: ser e parecer ser}

Sob uma perspectiva de caráter dramatúrgico, Goffman (1999, p. 9) leva em consideração o modo como o indivíduo, em situações triviais de trabalho, apresenta "a si mesmo e a suas atividades às outras pessoas, os meios pelos quais dirige e regula a impressão que formam a seu respeito e as coisas que pode ou não fazer, enquanto realiza seu desempenho diante delas". Usando, então, um modelo teatral para representar as coisas reais, o autor afirma que, em um palco, há uma correlação de três elementos: o ator que se apresenta atrás da máscara de um personagem, em conjunto com outros atores e seus respectivos personagens direcionados a uma plateia. $\mathrm{Na}$ vida real, esses elementos se restringem a dois: o papel que um indivíduo desempenha é dividido conforme os papéis que os outros 
desempenham, sendo que esses "outros" formam, também, a plateia.

A expressividade do indivíduo e, por conseguinte, sua capacidade de dar impressão, parece abarcar dois tipos extremamente distintos de atividade, segundo o autor referido: uma é a expressão que ele transmite e a outra é a expressão que ele emite. A primeira envolve "os símbolos verbais, ou seus substitutos, que ele usa propositadamente e tão só para veicular a informação que ele e os outros sabem estar ligada a esses símbolos" (GOFFMAN, 1999, p. 12). A expressão que o sujeito emite, por sua vez, compreende uma vasta gama de ações, que os outros podem achar sintomáticas do ator, supondo que a ação foi realizada por outros motivos, diferentes da informação como foi transmitida. Essa premissa, no entanto, não é definitiva, pois o indivíduo, obviamente, pode transmitir informação falsa, propositadamente.

No dia-a-dia, as primeiras impressões são importantes em interações iniciais que precedem uma série de interações futuras, já que, como diz o ditado popular: "a primeira impressão é a que fica". Isso ocorre porque existe uma ideia comumente perpetuada de que se deve estabelecer o controle da situação em estágio inicial para evitar problemas posteriores decorrentes dessa atitude.

A sociedade está organizada tendo por base o princípio de que qualquer indivíduo que possua certas características sociais tem o direito moral de esperar que os outros o valorizem e o tratem de maneira adequada. Ligada a este princípio há um segundo, de que um indivíduo que implícita ou explicitamente dê a entender que possui certas características sociais deve, de fato, ser o que ele pretende ser. Consequentemente, quando um indivíduo projeta uma definição da situação e com isso pretende, implícita ou explicitamente, ser uma pessoa de determinado tipo, automaticamente exerce uma exigência moral sobre os outros, obrigando-os a valorizá-lo e a tratá-lo de acordo com o que as pessoas de seu tipo têm o direito de esperar. Implicitamente, também renuncia a toda pretensão de ser o que não aparenta ser, e, portanto, abre mão do tratamento que seria adequado a tais 
pessoas. Os outros descobrem, então, que o indivíduo os informou a respeito do que é e do que eles devem entender por "é” (GOFFMAN. 1999, p. 21).

Para impedir embaraços e constrangimentos, os sujeitos, geralmente, usam práticas preventivas e, para compensar ocorrências desfavoráveis que não foram evitadas com sucesso, eles empregam práticas corretivas. De acordo com o estudioso, quando o indivíduo utiliza estratégias para proteger suas próprias projeções, pode-se considerá-las como práticas defensivas. Já as práticas protetoras ou de diplomacia ocorrem quando um indivíduo utiliza táticas para resguardar a projeção realizada por outro.

Ao desempenhar um papel, o indivíduo, de forma implícita, convida seus observadores a acreditarem em sua representação e que, de modo geral, as coisas devem ser o que parecem ser. Goffman (1974) denomina figuração ou trabalho de face (facework), tudo o que uma pessoa empenha para que suas ações não façam ninguém perder a face, incluindo ela própria. Segundo Preti (2002, p. 54), "a perda da face, em geral, pode levar a uma situação tensa e comprometedora da situação".

\section{Atenuação: marcadores e procedimentos}

Ao manifestar suas opiniões, seja em uma interação ou em entrevistas televisivas, o falante acaba deixando sua face exposta. Para que ela não seja arranhada frente a seus interlocutores, ele utiliza procedimentos que, de certo modo, o distanciam de seu enunciado.

É importante salientar a diferença entre marcadores e procedimentos de atenuação. A atenuação inclui uma enorme variedade de meios ou procedimentos de atenuação e refere-se à modificação de um ato de fala por meio do emprego de variados meios atenuadores. Um desses meios são os marcadores de atenuação, que correspondem às margens de uma unidade 
discursiva $^{5}$ e, comumente, são expressos por uma ou duas palavras. Eles diferem dos procedimentos de atenuação, que podem ser, em grande parte, enunciados inteiros.

O emprego desses marcadores ou expressões atenuadoras em uma entrevista serve para abrandar as situações de polêmica e evitar confrontos diretos com os ouvintes para a construção de uma imagem positiva do locutor. Segundo Galembeck (2002, p. 85):

os marcadores de atenuação com marcas de subjetividade preservam a auto-imagem construída pelo falante (face), e são igualmente utilizados para provocar no ouvinte o efeito desejado. Essa dupla destinação constitui uma evidência bastante positiva acerca do fato de que a noção de sujeito é binária e transitiva: a marca do sujeito traz, em si, o reconhecimento de que essa marca assinala a presença em face do interlocutor.

Observa-se, principalmente nas últimas entrevistas, o uso de perguntas diretas, por parte dos entrevistadores, cobrando uma posição do presidente, favorável ou contrária à união entre pessoas do mesmo sexo. No caso de perguntas diretas, percebese que o presidente empregou tais procedimentos para reduzir a força ilocutória de seus enunciados.

\subsection{Marcadores conversacionais}

Em uma interação face a face, há, frequentemente, o uso de diversas expressões e palavras mais ou menos convencionalizadas. Esse acordo verbal ocorre conforme o grau

\footnotetext{
${ }^{5}$ Castilho (1989, p. 253) afirma que a unidade discursiva é "um segmento do texto caracterizado semanticamente por preservar a propriedade de coerência temática da unidade maior, atendo-se como arranjo temático secundário ao processamento de um subtema, e formalmente por se compor de um núcleo e de duas margens, sendo facultativa a figuração destas". O termo diretora significa uma unidade discursiva "hierarquicamente superior" do ponto de vista de sua importância para a negociação (ROSA, 1992, p.63).
}

112 Horizontes de Linguística Aplicada, ano 11, n. 2, jul./dez. 2012 
de fixidez das formas linguísticas utilizadas em determinados contextos, pois, segundo Tannen (1985), todo significado na linguagem deriva, pelo menos parcialmente, de convenção. Com o avanço dos estudos acerca dessas constantes ocorrências na linguagem, passou-se a utilizar o termo marcador para definir as expressões e palavras que são normalmente fixas e convencionalizadas.

Os marcadores, de um modo geral, constituem um recurso imprescindível no texto falado, pois atuam no discurso de modo a organizar a função textual-interativa, estabelecendo relações entre unidades discursivas dos enunciados. Os marcadores não possuem um consenso terminológico entre os estudiosos, sendo chamados de marcadores conversacionais, marcadores discursivos, operadores discursivos, marcadores de estruturação da conversação, ou apoios do discurso.

A denominação adotada neste artigo para os marcadores presentes nas entrevistas é a mesma utilizada por Marcuschi (1989, p. 282) - marcadores conversacionais (MC) - que, de acordo com o autor, são palavras e expressões mais ou menos fixas, características da fala, elementos multifuncionais que "operam simultaneamente como organizadores da interação, articuladores do texto e indicadores de força ilocutória".

Por se tratar de um termo mais recorrente, muitos autores utilizam o conceito de marcadores discursivos. Esse termo é considerado neutro por abranger todos os marcadores que estão ligados à organização textual e à articulação interacional, diferentemente do conversacional, que trata, exclusivamente, do texto falado.

Fraser (1994, p. 157) propõe que "os marcadores discursivos não são formas de conteúdo disfarçadas em outra entidade, eles não constituem um grupo casual de expressões", mas devem ser vistos como uma categoria pragmática definida na gramática de uma língua.

No dizer de Risso, Silva e Urbano (1997, p. 21):

trata-se de um amplo grupo de elementos de constituição bastante diversificada, envolvendo, no plano verbal, sons não lexicalizados, palavras, 
locuções e sintagmas mais desenvolvidos, aos quais se pode atribuir homogeneamente a condição de uma categoria pragmática bem consolidada no funcionamento da linguagem. Por seu intermédio, a instância de enunciação marca presença forte no enunciado, ao mesmo tempo em que se manifestam importantes aspectos que definem sua relação com a construção textual-interativa.

Conforme Schiffrin (2003, p. 57), "os marcadores discursivos poderiam ser considerados como um conjunto de expressões linguísticas, compostas de membros de classes de palavras, tão variadas quanto as conjunções (ex.: $e$, mas, ou), as interjeições (oh), os advérbios (agora, então) e locuções lexicalizadas (sabe, quero dizer)" ${ }^{\prime \prime}$. A autora também considera o grau em que os marcadores conferem, eles próprios, sentido ao discurso, ou refletem um significado já aceitável, semanticamente. Um exemplo do primeiro caso seria a análise de quando o marcador oh exibe uma informação nova, inesperada, e do segundo, quando o marcador mas expressa um claro significado constrastivo (p. 58).

Para Marcuschi (2006, p.61), “existem relações estruturais e lingüísticas entre a organização da conversação em turnos (marcados pela troca de falantes) e a ligação interna em unidades constitutivas de turno." Assim, os marcadores exercem tanto funções discursivas quanto sintáticas e servem de elo entre unidades comunicativas, direcionando os interlocutores. Trata-se de recursos coesivos que assinalam os limites da comunicação: início e fim. $\mathrm{O}$ autor classifica esses marcadores em verbais, não-verbais ou paralinguísticos e suprassegmentais.

Os recursos verbais são os que formam uma categoria de palavras ou expressões estereotipadas e de grande ocorrência. Embora geralmente não forneçam informações novas para o

${ }^{6}$ discourse markers could be considered as a set of linguistic expressions comprised of members of word classes as varied as conjunctions (e.g. and, but, or), interjections (oh), adverbs (now, then), and lexicalized phrases (y'know, I mean)

114 Horizontes de Linguística Aplicada, ano 11, n. 2, jul./dez. 2012 
desenvolvimento do tópico, contribuem para situá-lo no contexto geral ou particular da conversação.

Os recursos não-verbais ou paralinguísticos compreendem as marcas representadas pelos gestos e pelas expressões faciais (risos, gestos, olhares, entre outros). Operam como mantenedores e reguladores do contato na interação face a face.

Os recursos suprassegmentais configuram-se como elementos de natureza linguística, porém, não de caráter verbal. Referem-se à prosódia (tom de voz, ritmo, pausas, entoação, entre outros). No caso das pausas, há de se levar em consideração seu papel decisivo na organização do discurso conversacional. Podem apresentar-se como pausas curtas (micropausas), médias ou longas, e são comuns em final de unidades comunicativas. São utilizadas, também, junto a outros marcadores.

Diante do exposto, é oportuno assinalar que os marcadores não compreendem somente as expressões frequentemente utilizadas pelos falantes, mas envolvem, também, aspectos interacionais, textuais, cognitivos e finalísticos da linguagem. Suas funções são muito abrangentes e, por isso, deve-se considerar o papel que exercem na conversação, em cada situação de uso.

\subsection{Marcadores de opinião}

Os marcadores de opinião são elementos altamente estereotipados e que denotam a incerteza da enunciação do locutor a respeito do que é dito. Servem para afastar ou atenuar a ligação do locutor com seu enunciado. Segundo Rosa (1992, p. 45), "esses marcadores abrangem expressões verbais, locuções adverbiais e pequenas frases prefaciadoras e posfaciadoras".

É importante ressaltar que determinados marcadores de opinião podem possuir valor atenuativo, contribuindo para reduzir a responsabilidade do falante em relação ao que está sendo exposto, pois evidenciam uma opinião pessoal e manifestam a subjetividade. 
A expressão verbal de opinião mais utilizada pelo presidente Barack Obama nas entrevistas analisadas foi a expressão I think e suas variações que, em português, correspondem a eu acho (que), penso (que). Podendo ocorrer tanto em posição inicial quanto intermediária e final, esse marcador demonstra a noção de incerteza em face às unidades discursivas, principalmente quando está em posição intermediária, como em inserções parentéticas, ou à direita da unidade discursiva.

Os marcadores prefaciadores de opinião têm uma função de emoldurar a fala. Em entrevistas televisivas, esse recurso é bastante utilizado quando se trata de tópicos polêmicos, pois o entrevistado quer se certificar de que o entrevistador/interlocutor esteja compreendendo e interpretando seu discurso do modo intencionado. Seu emprego visa, ainda, a afastar possíveis tipificações negativas e atos ameaçadores à face do interlocutor.

Ocorreu, também, uma grande utilização, por parte do presidente, dos marcadores prefaciadores metadiscursivos que, segundo Rosa (1992), são considerados não apenas como unidades isoladas de significação, mas como uma função preparatória para a ocorrência da unidade discursiva. Conforme a autora, "é inegável que algumas dessas expressões remetem de forma privilegiada a uma moldura cognitiva que prepara o que vai ser dito adiante" (p. 64).

Em uma interação, os marcadores prefaciadores metadiscursivos servem para anunciar a realização do ato ilocutório para antecipar uma possível ameaça às faces dos interlocutores com o fim de minimizá-la. A ação de anunciar o que vai ser dito a seguir torna menos ameaçadora a ação subsequente, minimizando os riscos contidos na declaração vindoura.

\section{Análise e discussão dos dados}

Em relação à constituição do corpus, começa-se, neste artigo, analisando a primeira entrevista do presidente Barack Obama, concedida no ano de 2004, época em que concorria a 
presidência do senado. Optou-se por trabalhar as entrevistas de forma cronológica para evidenciar a mudança de opinião e os procedimentos atenuadores similares presentes em todas as entrevistas analisadas.

Na primeira entrevista (OBAMA, 2004), observa-se por parte do entrevistador Phil Ponce, jornalista de televisão de Chicago e apresentador do programa noturno de notícias Chicago Tonight, a consciência da polêmica existente no casamento entre pessoas do mesmo sexo. $\mathrm{O}$ mediador utilizou os princípios cristãos para questionar o posicionamento de Obama em relação ao casamento gay. A pergunta poderia ter sido feita de modo direto, dando abertura para justificar sua resposta, porém, ao apresentar, de antemão, um posicionamento contrário à união gay baseando-se na fé religiosa professada por Obama, a pergunta tornou-se ameaçadora por exigir uma tomada de partido.

ENTREVISTADOR: Mr. Obama you said that your religious faith... your religious faith dictates that marriage should be between a man and a woman... would you elaborate on that? PRESIDENTE OBAMA: Well... what I believe is that... is that marriage is between a man and a woman... but what I also believe is that we have an obligation to make sure that gays and lesbians have the rights of citizenship that afford them visitations to hospitals that allow them to be ah::: to transfer property between partners to make certain that they're not discriminate on the job I think that... (...) (OBAMA, $2004)^{7}$

\footnotetext{
${ }^{7}$ ENTREVISTADOR: Senhor Obama você disse que a sua fé religiosa... a sua fé religiosa determina que o casamento deveria ser entre um homem e uma mulher... você poderia falar mais sobre isso? (Obama, 2004)

PRESIDENTE OBAMA: Bem... o que eu acredito é que... é que o casamento seja entre um homem e uma mulher... mas o que eu também acredito é que nós temos a obrigação de nos certificar de que gays e lésbicas tenham os direitos de cidadania que lhes garantem visitas aos hospitais que lhes permitem ser ah::: de transferir bens entre os parceiros para ter certeza de que eles não sejam discriminados no trabalho eu acho que... (...) (Obama, 2004)
} 
Ao responder a pergunta, Obama, que nessa entrevista demonstrou ser contrário ao casamento gay, expressou seu ponto de vista utilizando os marcadores de opinião. O marcador prefaciador "Well... what I believe" (Bem... o que eu acredito), além de ter uma função de emolduramento na unidade discursiva, serve para anunciar um ponto de vista baseado em sua fé.

Após expressar o seu ponto de vista contrário ao casamento gay, Obama tentou resguardar sua face ao utilizar um marcador prefaciador de opinião "but what I also believe" (mas o que eu também acredito). Essa estratégia apresenta uma ideia diferente daquela apresentada anteriormente, rejeitando, de antemão, possíveis reações desfavoráveis ao que foi dito na unidade discursiva, evitando o julgamento negativo dos ouvintes favoráveis ao casamento gay.

Ao afirmar que gays e lésbicas devem ter direitos garantidos, como visitas em hospitais, transferência de propriedades entre os parceiros e a não discriminação no trabalho, Obama amenizou seu posicionamento perante a comunidade gay. Vale ressaltar que na época em que concorria ao senado, o apoio dos homossexuais não era decisivo para o êxito político, sendo mais proveitoso para sua campanha evidenciar as qualidades de um pai de família, religioso e que respeita as diferenças, do que se envolver em uma causa tão polêmica.

A linha de pensamento de Obama foi interrompida ao ser questionado, dessa vez de forma direta, sobre o que em sua fé religiosa o fazia ser contra o casamento gay:

ENTREVISTADOR: Excuse-me but as far as... why/what in your religious faith... calls you to be against... gay marriage? (OBAMA, 2004) ${ }^{8}$

Para responder a essa pergunta, Obama recorreu ao mesmo recurso utilizado na pergunta anterior: usou os

\footnotetext{
${ }^{8}$ ENTREVISTADOR: Me desculpe mas até onde... por que/o que na sua fé religiosa... o faz a ser contra... o casamento gay?
}

118 Horizontes de Linguística Aplicada, ano 11, n. 2, jul./dez. 2012 
marcadores prefaciadores para expressar seu ponto de vista, e acrescentou, ao utilizar "but I also think" (mas eu também acho), pontos que devem ser levados em consideração na união gay.

PRESIDENTE OBAMA: What I believe... in my faith... is that ah... a man and a woman... when they get married are performing something before God and it's not simply... ah the two... ah:: persons who are meeting... ah but that doesn't me::an that that necessarily translates into a position on public policy or... ah with respect to civil unions... what it does mean is the/is that we have a set of traditions in place... that I think... ah need to be preserved... but I also think that we have to make sure that gays and lesbians have the same set of basic rights... ah:: that are in place and I was glad to see for example the president today apparently stated that he was in favor of civil unions this may be a reversal of his position... (OBAMA, 2004) ${ }^{9}$

Nesse trecho, podemos perceber um consenso religioso da sociedade conservadora refletido na fala de Obama quando disse "we have a set of traditions in place... that I think... ah need to be preserved" (nós temos um conjunto de tradições instituídas... que eu acho que... ah precisam ser preservadas). Esse conjunto de tradições que precisa ser preservado refere-se ao laço matrimonial entre homens e mulheres. A utilização do marcador I think (eu acho) tenta atenuar a força ilocutória diante dos homossexuais, pois valoriza as tradições compartilhadas pela sociedade americana. Ao utilizar o pronome we (nós),

\footnotetext{
${ }^{9}$ PRESIDENTE OBAMA: $O$ que eu acredito... na minha fé... é que ah... um homem e uma mulher... quando eles se casam estão realizando algo diante de Deus e não é simplesmente... ah as duas... ah:: pessoas que estão reunidas... ah mas isso não signifi::ca que que necessariamente se traduza em uma posição acerca de política pública ou... ah no que diz respeito a uniões civis... o que realmente significa é o/ é que nós temos um conjunto de tradições instituídas... que eu acho que... ah precisam ser preservadas... mas eu também acho que nós temos que ter certeza de que gays e lésbicas tenham o mesmo conjunto de direitos básicos... ah:: que estão em vigor e eu fiquei contente de ver por exemplo o presidente hoje aparentemente afirmou que ele era a favor de uniões civis isso talvez seja uma reversão de sua posição.
} 
Obama transferiu a responsabilidade para a coletividade e eximiu-se de uma postura enfática.

Durante essa entrevista, foram utilizados vinte e duas vezes o marcador de opinião I think (eu acho) e suas variações $I$ don't think (eu não acho) e I believe (eu acredito), o que indica uma determinada incerteza do locutor a respeito do que diz. $\mathrm{O}$ seu papel pode ser o de manifestar uma opinião do locutor bem como atenuar e preservar a face diante do interlocutor. Como no trecho anterior, Obama utilizou o marcador I think (eu acho) para demonstrar uma opinião que identifica o casamento como uma instituição particular, e não como um direito civil, amenizando esse consenso ao transferi-lo à comunidade, como pode-se ver no segmento abaixo:

PRESIDENTE OBAMA: No... I think there are a whole host of things... that... are civil rights and then there are other things such as traditional marriage that $I$ think... express a community's concern and regard ah for a particular institution... (OBAMA,. 2004) $)^{10}$

A segunda entrevista analisada foi concedida em maio de 2012 a Robin Roberts, âncora do jornal ABC News. Além das entrevistas analisadas nesse artigo, foram encontradas três entrevistas de destaque em que Obama, já como presidente dos Estados Unidos, foi questionado acerca de seu posicionamento em relação ao casamento gay.

Em uma entrevista, de dezembro de 2010, o presidente afirmou que seus sentimentos quanto a esse assunto estavam em constante evolução. Em uma coletiva de imprensa da Casa Branca, em junho de 2011, Obama considerava uma questão importante a ser discutida por cada estado, entendendo que o resultado poderia variar de um local para outro. Ainda em 2011, no mês de outubro, é interessante observar que ao ser questionado sobre uma possível mudança de pensamento antes

\footnotetext{
${ }^{10}$ PRESIDENTE OBAMA: Não... eu acho que há uma série de coisas... que ... são direitos civis e então há outras coisas como o casamento tradicional que $e u$ acho que... expressam a preocupação e a consideração de uma comunidade ah por uma determinada instituição...
}

120 Horizontes de Linguística Aplicada, ano 11, n. 2, jul./dez. 2012 
das eleições presidenciais, Obama afirmou estar trabalhando sobre o assunto, ao se referir ao casamento gay, e que não iria "fazer notícias" naquele momento.

$\mathrm{Na}$ entrevista que será analisada a seguir, vê-se uma mudança de opinião: é a primeira vez que o presidente afirmou ser a favor do casamento gay. Ao ser indagado se ainda se opunha ao casamento entre pessoas do mesmo sexo, Obama não respondeu de imediato:

PRESIDENTE OBAMA: Well... you know... I have to tell you as I've said, I've/I've been going through an evolution on this issue... (...) I had hesitated on::: gay marriage... in part because I thought civil unions would be sufficient that that was something that would give people hospital visitation rights and ah... other... elements that we take for granted... ah:...and... I was sensitive to the fact that... for a lot of people... you know... the the word marriage was something that... evokes very powerful traditions... religious beliefs... and so forth... (OBAMA, 2012) ${ }^{11}$

A sentença em destaque constitui um segmento prefaciador utilizado por Obama como forma de adiantamento do conteúdo tópico durante a interação. O marcador well (bem) aliado às pausas é entendido aqui como uma forma de ganhar tempo diante da questão para formular sua resposta. Observa-se, também, que o uso do marcador conversacional you know (sabe), além de exercer a função de envolvimento do ouvinte, assume, ainda, a busca de aprovação discursiva em relação ao que foi dito, orientando o interlocutor quanto ao modo como deve interpretar o discurso.

11 PRESIDENTE OBAMA: Bem... sabe... eu tenho que te dizer como eu disse eu/ eu venho passando por uma evolução sobre esse assunto... (...) eu hesitei sobre::: o casamento gay... em parte porque eu pensei que as uniões civis seriam suficientes que que isso era algo que daria às pessoas os direitos de visitação hospitalar e ah ... outros... elementos que nós tomamos como garantidos... ah:... e... eu fiquei sensível ao fato de que.... para muitas pessoas que... sabe... a palavra casamento era algo que... evocava tradições muito poderosas... crenças religiosas... e assim por diante... 
Antes de responder a pergunta central, Obama realizou uma justificativa de sua resposta, ao dizer que estava em evolução sobre o assunto e que hesitou no casamento gay por acreditar que a união civil garantiria igualdade de direitos aos homossexuais. Ao admitir a causa de sua hesitação, Obama revelou que ela estava fundamentada no fato de que muitas pessoas consideram a palavra "casamento" impregnada de crenças religiosas.

PRESIDENT OBAMA: But I have to tell you that... over the course of... ah... several years as I talk to... friends and family and neighbors ah... when I think about... ah members of my own staff who are incredibly committed in monogamous relationships same-sex relationships... who are raising kids together... when I think about... those soldiers or airmen or marines or... ah sailors who are out there fighting on my behalf ah:: and yet feel constrained even now that Don't Ask Don't Tell is gone... because... they're not able to... commit themselves in a marriage... ah:: at a certain point I've just concluded that... ah for me personally (+) it is important for me to go ahead and affirm... that... ah I think same-sex couples should be able to get married... now... I have to tell you that... part of my hesitation on this has also been... (OBAMA, 2012)

Novamente, Obama minimiza a ameaça à face diante do público gay ao atribuir sua decisão, anteriormente contrária, a

${ }^{12}$ PRESIDENTE OBAMA: Mas eu tenho que te dizer que... ao longo dos... ah... vários anos como eu falo com... amigos e familiares e vizinhos ah... quando eu penso nos... ah membros da minha própria equipe que são incrivelmente comprometidos em relações monogâmicas relações com pessoas do mesmo sexo... que estão criando filhos juntos... quando eu penso naqueles... soldados ou aviadores ou fuzileiros ou... ah marinheiros que estão lá fora lutando em meu nome ah:: e ainda que se sintam constrangidos mesmo agora que Não Pergunte Não Conte já não existe... porque... eles não são capazes de... se comprometerem em um casamento... ah:: em um certo ponto eu acabei de concluir que... ah para mim pessoalmente $(+)$ é importante para mim ir em frente e afirmar... que... ah eu acho que casais do mesmo sexo devem poder se casar... agora... eu tenho que te dizer que... parte da minha hesitação por isso também tem sido...

122 Horizontes de Linguística Aplicada, ano 11, n. 2, jul./dez. 2012 
um conjunto de crenças que considerava ser da maioria, ou seja, a influência exercida por grande parte da população era o principal motivo que o levava a ir contra o casamento gay.

Em seguida, ao justificar a mudança em relação ao casamento gay, o presidente realizou a armação do quadro tópico por citar diversos motivos que o levaram a mudar de decisão, entre eles: a opinião de amigos, família, vizinhos, funcionários do seu próprio governo que são a favor do casamento entre pessoas do mesmo sexo. Obama ainda ressaltou que, embora seu governo tenha acabado com a política conhecida como Don't Ask Don't Tell, que proibia os militares de assumirem sua orientação sexual, os soldados não são capazes de estabelecer um casamento. A armação do quadro tópico fornece bases para justificar sua mudança de opinião e preservar a face perante o público.

\section{Considerações finais}

Observa-se, no corpus, que o uso dos marcadores e procedimentos atenuadores está relacionado com a preocupação em preservar a face diante de públicos distintos. Na primeira entrevista, o presidente empregou os procedimentos e marcadores de opinião para se distanciar da polêmica. Já na segunda entrevista, o posicionamento de Obama em relação ao casamento gay foi diferente. Dessa forma, os procedimentos atenuadores passaram a ser utilizados com o propósito de preservar a face diante da mudança de opinião.

Os marcadores de atenuação, nos casos analisados, podem proteger tanto a face do falante, como a de seu interlocutor. Embutidos na unidade discursiva, esses procedimentos ocorrem, muitas vezes, de forma sutil e visam a negociar a identidade social do falante, ou seja, a face que deseja exibir ou preservar. Obama utilizou os procedimentos atenuadores, ora para se aproximar da população que é contra o casamento gay, ora para se aproximar dos que são a favor.

É importante ressaltar que o presidente empregou, frequentemente, os marcadores prefaciadores, que têm a função 
de anunciar o que será dito. Esses marcadores previnem uma possível ameaça às faces, pois antecipam as reações negativas dos interlocutores e promovem um emolduramento da unidade discursiva. Cabe assinalar que os procedimentos de atenuação contribuem para diminuir a força ilocutória dos enunciados, abrandar efeitos de sentido não convenientes aos interesses e propósitos do falante, resguardando, assim, sua imagem positiva para obter o assentimento dos ouvintes.

\section{Referências}

CASTILHO, Ataliba T.. Para o estudo das unidades discursivas no português falado. In: . (Org.). Português culto falado no Brasil. Campinas: Ed. Unicamp. 1989. p. 249-280

- A língua falada no ensino de português. 2 ed. São Paulo: Contexto, 2000.

FRASER, Bruce. Uma abordagem sobre os marcadores discursivos. Confluência. Boletim do Departamento de Lingüística. Universidade Estadual Paulista. Faculdade de Ciências e Letras. Assis, SP, ano 2, n. 2, p. 132-160, 1994.

GALEMBECK, Paulo T. Marcas da subjetividade e intersubjetividade em textos conversacionais. In: PRETI, Dino. (Org.). Interação na fala e na escrita. São Paulo, Humanitas/FFLCH/USP, 2002. p. 67-88.

O turno conversacional. In: PRETI, Dino (Org.). Análise de textos orais. 6 ed. São Paulo: Humanitas Publicações FFLCH/USP (Projetos Paralelos). V 1, 2003. p. 65-92.

GOFFMAN, Erving. Les rites d'interaction. Paris: Les Éditions de Minuit, 1974.

A representação do eu na vida cotidiana. 8 ed. Tradução de Maria Célia Santos Raposo. Petrópolis: Vozes, 1999.

124 Horizontes de Linguística Aplicada, ano 11, n. 2, jul./dez. 2012 
PRETI, Dino. Alguns problemas interacionais da conversação. In: . (Org.). Interação na fala e na escrita. Publicação do Projeto de Estudo da Norma Lingüística Urbana Culta de São Paulo (Projeto Nurc/SP - Núcleo USP). São Paulo: Humanitas/ FFLCH/USP, 2002. p.45-66.

(Org.) Análise de textos orais. 6 ed. São Paulo: Humanitas Publicações FFLCH/USP. (Projetos ParalelosNURC/SP). V 1. 2003.

MARCUSCHI, Luiz Antônio. Marcadores conversacionais no português brasileiro: formas, posições e funções. Campinas: Unicamp, 1989.

. Análise da conversação. 5 ed. São Paulo, Ática, 2006.

OBAMA, Barack. I don't think marriage is a civil right: depoimento.[26 de outubro, 2004]. Real Clear Politics. Entrevista concedida a Phil Ponce. Disponível em <http://www.realclearpolitics.com/video/2012/05/08/obama_in_ 2004_i_dont_think_marriage_is_a_civil_right.html>. Acesso em: 14 jul. 2012.

Robin Roberts $A B C$ News interview with President Obama: depoimento. [09 de maio, 2012]. ABC NEws. Entrevista concedida a Robin Roberts. Disponível em <http://abcnews.go.com/Politics/transcript-robin-roberts-abcnews-interview-president-obama/story?id=16316043>. Acesso em: 20 jul. 2012.

RISSO, Mercedes S.; SILVA, Giselle M. O.; URBANO, Hudinilson. Marcadores discursivos: traços definidores. In: KOCH, Ingedore G. V. (Org.). Gramática do português falado. Campinas: Unicamp/FAPESP. V VI. Desenvolvimentos, 1997. p. 21-94.

SCHIFFRIN, Deborah. Discourse markers: language, meaning, and context. In: SCHIFFRIN, Deborah; TANNEN, Deborah; 
HAMILTON, Heidi. The handbook of discourse analysis. Malden: Blackwell Publishing, 2003. p. 54-75.

TANNEN, Deborah. The oral/literate continuum in discourse. In: _ (Ed.). Spoken and written language: exploring orality and literacy. Norwood: N. J. Ablex. 1982. p. 1-16.

Recebido em: 01/10/2012 Aceito em: 02/03/2013

Title: Mitigation devices in spoken English: President Obama's speech 